\title{
LA EDUCACIÓN SUPERIOR EN AMÉRICA LATINA Y EL CARIBE
}

Tunnermann Berheim, Carlos (editor) La educación superior en América Latina y el Caribe: diez años después de la Conferencia Mundial de 1998. Cali: IESALC-UNESCO, PUJ, 2008, 404 págs.

El libro compila un conjunto de investigaciones, de diferentes autores, sobre las transformaciones y tendencias que han caracterizado el desarrollo reciente de los sistemas nacionales de educación superior en la región. Su foco está puesto en la influencia que la "Declaración Mundial sobre la Educación Superior en el siglo XXI: visión y acción" y el "Marco de acción prioritaria para el cambio de desarrollo de la Educación Superior", suscritos en la Conferencia de la UNESCO (CMES) celebrada en París en 1998, han ejercido sobre nuestras políticas, instituciones y prácticas para esta clase de educación. El libro parte de la base que la Declaración Mundial ha constituido, en primer lugar, una forma de orientación normativa cuya significación se vuelve relevante en el contexto de una especie de crisis de la educación superior con sentido público, en la cual la gravitación adquirida por el mercado en la coordinación de las instituciones genera en ellas un vacío respecto de su misión como aporte para el desarrollo nacional. En segundo lugar, el Marco de Acción Prioritaria contiene una propuesta de buenas prácticas que, al cabo de 10 años de ser incorporadas en los instrumentos nacionales de política para la educación superior, debiera ser posible evaluar y comprobar si efectivamente han conducido a ajustar el funcionamiento de los sistemas nacionales hacia mejores desempeños, de acuerdo con los propósitos de desarrollo social en la región.

El libro consiste en un ejercicio de seguimiento sobre los compromisos adquiridos en la Declaración Mundial de la UNESCO, y sobre el impacto de las acciones introducidas siguiendo el Marco de Acción Prioritaria, con el fin de servir como referente teórico 
y documento base para la discusión de la Conferencia Regional de Educación Superior, CRES 2008, celebrada recientemente en Cartagena de Indias, como preparación para la Cumbre Mundial de Educación Superior París + 10 .

A medida que se avanza en la lectura del texto, se adquiere una claridad particular sobre la función que organismos multilaterales, como UNESCO, MERCOSUR o el Banco Mundial, han tenido en incentivar, mediante políticas, recursos, acuerdos, instrumentos y apoyo técnico, el desarrollo de los sistemas de educación superior en direcciones específicas, no siempre coherentes entre sí. Tomemos, por ejemplo, las discusiones asociadas al concepto de calidad. Por una parte, ésta ha sido abordada desde una perspectiva más economicista, es decir, como una necesidad de rendición de cuentas y efectividad en el contexto de la expansión y diversificación de la oferta de la educación superior. Así, también, el aseguramiento de la calidad de la formación terciaria se ha articulado como respuesta a los requerimientos de reconocimiento de títulos entre los países de la región y como una condición para la internacionalización de los estudios y mercados de profesionales. Por último, con un énfasis más político, la calidad ha sido planteada como pertinencia social, es decir, como atributo de un tipo educación que da garantías a la sociedad de estar al servicio de un proyecto ético de país, pues se basa en conocimientos que son usados con fines emancipatorios, como contribución al desarrollo social. De alguna forma, los organismos multilaterales han tendido a reforzar perspectivas diferentes de lo que es la calidad, estableciendo metas que no siempre son coincidentes y estimulando cambios en direcciones que a veces pueden ser contradictorias.

El libro se integra por el trabajo de diversos contribuyentes y recoge las discusiones realizadas en el marco del proyecto "Tendencias de la Educación Superior en América Latina y el Caribe". Se logra abarcar una amplia gama de áreas, en las cuales se identifican avances y también situaciones de estancamiento con relación a los compromisos asumidos en la Conferencia Mundial. La educación superior de la región es analizada desde el punto de vista de sus transformaciones 
institucionales, organizacionales, curriculares y de financiamiento, considerando en estos cambios los esquemas de aseguramiento de la calidad, el efecto de la incorporación de tecnologías, los nuevos roles y desafíos de las instituciones en la sociedad del conocimiento, y por sobre todo identificando los actores que han participado y conducen los actuales estilos de desarrollo de la educación superior.

Hay que destacar que el punto de vista del análisis es fundamentalmente académico: esta es la perspectiva dominante al considerar las dinámicas de la educación superior y evaluar los avances introducidos por el Marco de Acción Prioritaria. El libro indica cómo se ha avanzado en cobertura y también en la ampliación de las oportunidades de estudio continuo. Sin embargo, este proceso no ha ido acompañado de una modificación funcional de los currículos. Se reconoce, asimismo, la implantación efectiva de una cultura de la informática (uso de tecnología en la educación superior), de una cultura de la evaluación y de la calidad. No obstante, se plantea que falta relevar un concepto de calidad anclado en la pertinencia social, no sólo laboral o de acuerdo con los requerimientos de productividad económica. También se advierte que, con relación a la investigación, el despliegue de capacidades de la región no ha sido suficiente, manteniendo una relación dependiente respecto de los países desarrollados y exhibiendo asimetrías de rendimiento entre áreas del conocimiento. Se plantea que ha habido avances en cuanto a la gestión institucional pero, al mismo tiempo, no han sido poco frecuentes los conflictos entre ésta y los intereses propiamente académicos. La idea de que las universidades orienten su trabajo directamente hacia áreas de impacto social no parece haber encausado una práctica sistemática en la región, ni tampoco los esquemas de financiamiento se han hecho cargo de proporcionar una base consistente para promover el desarrollo de todo el sistema de educación superior.

En síntesis, se trata de un libro que no deja apasionar, por su compromiso con el contenido de los objetivos y acciones asumidos como región en la conferencia mundial. Es difícil recoger del texto un balance general de los cambios, y en particular de los avances, de la 
educación superior en América Latina y el Caribe entre 1998 y 2008. Probablemente, su aporte se oriente más a dar cuenta de las brechas -de una forma más cualitativa que cuantitativa- y a proporcionar matices. Constituye, sin duda, un aporte a la reflexión sobre las finalidades de la educación superior en la región y contribuye además con aproximaciones académicas y también políticas sobre sus desafíos pendientes.

Nicolás Fleet Departamento de Estudios Comisión Nacional de Acreditación nfleet@cnachile.cl 